\title{
Oncological safety of intrafascial nerve- sparing radical prostatectomy compared with conventional process: a pooled review and meta-regression analysis based on available studies
}

\author{
Xiao Wang ${ }^{\dagger}$, Yiqi Wu', Jia Guo, Hui Chen, Xiaodong Weng and Xiuheng Liu*
}

\begin{abstract}
Background: Intrafascial prostatectomy was a modified technique from the conventional nerve-sparing surgery in order to improve patients' post-surgical continence and erectile function; however, ongoing controversy exists regarding the oncological safety of this technique. In this study we aimed to provide a critical and pooled analysis based on published literatures regarding the oncological outcomes after intrafascial nerve-sparing prostatectomy.

Methods: Database searches were performed for published articles till June 2018 on PubMed. Three reviewers screened fulfilled papers and extracted data independently. Main outcome was the positive surgical margins (PSMs) rates stratified by pathological stages. We performed both one-arm and comparative meta-analysis to evaluate the oncological safety of intrafascial technique. Moreover, we built meta-regression models to assess the confounding factors.

Results: We retrieved a total of 117 records after electronic search, of which 21 studies were finally included in this review. There were 15 controlled studies and 6 surgical series. Our one-arm meta-analysis demonstrated that the total PSM rates after intrafascial techniques ranging from 2.2 to $35 \%$, with a pooled rate of $14.5 \%$ on average (480 of 3151 patients, 95\% confidence interval[CI]: 11.2-17.5\%). Meta-regression model showed that patients' age, pT2 cancer percentage and Selection Score of Oncological Safety (SSOS) were significantly associated with total PSM rate; moreover, each 1 point of SSOS could decrease the total PSM rate by $1.3 \%$ on average. Comparative meta-analysis demonstrated that there was no significant difference between intra- and inter-fascial group regarding PSM rates.

Conclusions: With stringent case selection and when performed by experienced surgeons, intrafascial prostatectomy could offer an acceptable or, at least, equivalent PSM rate compared with the conventional interfascial approach. Preoperative SSOS more than 7 points could be considered as an indication of intrafascial radical prostatectomy.
\end{abstract}

Keywords: Oncological safety, Radical prostatectomy, Intrafascial nerve-sparing, Systematic review, Positive surgical margins

\footnotetext{
* Correspondence: prof_liuxhmd@163.com

${ }^{+}$Xiao Wang and Yiqi Wu contributed equally to this work.

Department of Urology, Renmin Hospital of Wuhan University, 238Jiefang

Road, Wuhan 430060, People's Republic of China
}

(c) The Author(s). 2019 Open Access This article is distributed under the terms of the Creative Commons Attribution 4.0 International License (http://creativecommons.org/licenses/by/4.0/), which permits unrestricted use, distribution, and reproduction in any medium, provided you give appropriate credit to the original author(s) and the source, provide a link to the Creative Commons license, and indicate if changes were made. The Creative Commons Public Domain Dedication waiver (http://creativecommons.org/publicdomain/zero/1.0/) applies to the data made available in this article, unless otherwise stated. 


\section{Background}

Radical prostatectomy is recommended as an effective treatment for clinically localized prostate cancer [1, 2], and used to cure patients with low/intermediate risk of disease [3]. Based on the updated anatomy understandings, the approaches to preserve peri-prostatic nerves have undergone many modifications from the conventional nerve-sparing surgery [4]. Intrafascial technique was a kind of refinements, characterized by developing a dissection plane medially/internally to the prostatic fascia, in order to maximally preserve peri-prostatic nerves and to enhance the post-surgical recovery of continence and potency. This technique is now applied worldwide in combination with different surgical approaches and procedures [5, 6].

Controversy about the intrafascial nerve-sparing technique has persisted since its introduction [7]. Most doubts were concentrated at its oncological safety, considering the necessity of removing all fascial coverings of the prostatic surface in resecting a tumor. It is generally recognized that the greater extent of structures spared, the higher is the risk of residual tumor; therefore, some surgeons would be concerned that intrafascial dissection would compromise its oncological safety and incur a risk of a higher rate of positive surgical margins (PSMs) [8].

There were obvious variations regarding the oncological results reported by different surgeons, which may be influenced by factors such as surgeon characteristics, surgical procedures, patient inclusion criteria, and outcome assessment methods. The purpose of this study was to critically summarize existing clinical trials and provide a detailed and comprehensive assessment of the oncological findings of intrafascial prostatectomy to guide urologists in selecting the appropriate technique.

\section{Methods}

\section{Inclusion criteria}

Inclusion criteria were set according to PICOS (patients, intervention, comparison, outcomes, and study design) principle as presented in Table 1. This review included

Table 1 PICOS principle of inclusion criteria

\begin{tabular}{ll}
\hline Criteria & Description \\
\hline Patients & $\begin{array}{l}\text { Adult men diagnosed as prostate cancer undergoing } \\
\text { radical prostatectomy }\end{array}$ \\
Intervention & $\begin{array}{l}\text { Intrafascial nerve-sparing radical prostatectomy, including } \\
\text { Veil, Leipzig, curtain dissection, or other techniques } \\
\text { approaching fascial planes on the surface of the } \\
\text { prostatic capsule or medial/internal to the prostatic } \\
\text { fascia, regardless of surgery types }\end{array}$ \\
Comparison & $\begin{array}{l}\text { Conventional interfascial nerve-sparing prostatectomy, } \\
\text { regardless of surgery types }\end{array}$ \\
Outcomes & PSM rates stratified by pathological stages \\
Study design & $\begin{array}{l}\text { Surgical series or prospective/retrospective controlled } \\
\text { studies, including RCTs }\end{array}$
\end{tabular}

PSM positive surgical margin, $R C T s$ randomized controlled trials trials designed as surgery series or controlled studies. Included studies had at least one arm that is performed using intrafascial techniques, including veil technique and other techniques approaching fascial planes close to the prostatic capsule and internal to the prostatic fascia, regardless of the types of surgery including retropubic radical prostatectomy (RRP), laparoscopic radical prostatectomy (LRP) and robot-assisted laparoscopic radical prostatectomy (RALRP). Study paralleling convetional interfascial technique was included in the comparative analysis as a control study. We excluded studies from the comparative assessment, including extra-fascial or wide-dissection or non-nerve-sparing prostatectomy, and for these studies we only extracted data from the intrafascial group.

\section{Data sources and searches}

Database searches were performed for published articles till June 2018 on PubMed. The following keywords were used across the "Title" and "Abstract" field including: ("intrafascial" OR "veil" OR "curtain dissection" OR "incremental nerve sparing" OR "high anterior release") AND "radical prostatectomy". Study characteristics were in accordance with our PICOS principle. There were no restrictions on the reporting characteristics of the publication status or language. In addition, there were no restrictions on the time of surgery or the date of publication. We manually checked the reference list of the included studies to further identify other relevant studies. Three reviewers (JG, HC, XW) independently screened the titles, abstracts and keywords of each search article. If the study met the inclusion criteria, we screened the full text for further evaluation. We excluded duplicate publications or superficially reported studies. Disagreements were resolved through open discussion.

\section{Data extraction and synthesis}

Data were independently extracted by three reviewers (JG, HC, XW) using standard formats, including study characteristics, patient characteristics, surgical information and outcomes. The authors of the original study were consulted for the missing data if needed. As surgical margins were confounded by patient selection, we evaluated and scored the patients' preoperative risk level according to the nomogram of Partin tables [9] along with D'Amico's study [10]. The scoring scale shown in Table 2 is stratified into 4 parts including clinical tumor stage, preoperative PSA level, Gleason score and invaded cores percentage. The scores of the 4 parts were summed up to the Selection Score of Oncologic Safety (SSOS). A high score indicated a more rigorous patient selection criteria and low risk of extraprostatic extension and margin involvement. 
Table 2 Scoring scale of Selection Score of Oncologic Safety

\begin{tabular}{|c|c|c|c|c|c|c|c|c|c|c|c|c|}
\hline Section & \multicolumn{6}{|c|}{ Clinical T stage } & \multicolumn{6}{|c|}{ Preoperative PSA level (ng/ul) } \\
\hline Item & T1c & T2a & $\mathrm{T} 2 \mathrm{~b}$ & $\mathrm{~T} 2 \mathrm{C}$ & $\mathrm{T} 3$ & NS & $0-2.5$ & $2.6-4$ & $4.1-6$ & $6.1-10$ & $>10$ & NS \\
\hline Score & 5 & 4 & 3 & 2 & 1 & 0 & 5 & 4 & 3 & 2 & 1 & 0 \\
\hline Section & \multicolumn{6}{|c|}{ Biopsy Gleason score } & \multicolumn{6}{|c|}{ Invaded cores percent (\%) } \\
\hline Item & $2-4$ & $5-6$ & $3+4$ & $4+3$ & $8-10$ & NS & $<34$ & $34-50$ & & $>50$ & & NS \\
\hline Score & 5 & 4 & 3 & 2 & 1 & 0 & 3 & 2 & & 1 & & 0 \\
\hline
\end{tabular}

This scoring scale was according to the Partin table and D'Amico's study, stratified to 4 parts including clinical stage, preoperative PSA level, Gleason score and invaded cores percent. Scores of the 4 parts were summed to the Selection Score of Oncologic Safety (SSOS). High score means the more rigorous selection criteria for patients and low risk of extraprostatic extension and margin involvement. PSA prostate-specific antigen, NS not evaluated

With regard to a comparative analysis of the PSM rate, some studies had a selection bias between the intra- and inter-fascial groups. As surgeons often doubted the oncological safety of the intrafascial technique, they restricted the application of this technique to patients with early-stage tumors and lower risk of extraprostatic extension, but employed the interfascial procedure in high-risk disease. We considered this bias as a selection imbalance and, if surgeons made no exception in the selection of patients, we judged this as selection balance.

\section{Bias assessment}

The Cochrane Collaborative Bias Assessment Tool was used to assess the methodological quality of the included control studies. The following items were evaluated: (1) Adequate sequence generation? (2) Allocation concealment? (3) Binding? (4) Incomplete outcome data addressed? (5) Free of selective reporting? (6) Free of other bias? Each question was rated as "low risk", "high risk" or "unclear" and three reviewers (JG, HC and XW) independently assessed each trial. We used the funnel plot to evaluate publication bias. If there is a disagreement, judgment was made through public discussion.

\section{Data analysis}

All data extracted from the intrafascial arms were pooled using Open Meta-analyst software, stratified by surgical type. We performed one-arm meta-analysis using random effects models, and heterogeneity in the studies was assessed using Chi-square test and the $\mathrm{I}^{2}$ index. Meta-regression analysis was performed with total PSM rate as a dependent variable, including patient age, preservation techniques, pT2 cancer percentage, and SSOS as covariate variables. An in-depth regression analysis was performed by including each part of the SSOS and excluding each part from the SSOS.

Comparative meta-analysis was conducted with the Cochrane Collaboration Review Manager. Heterogeneity among the studies was assessed using Chi-square test and the $\mathrm{I}^{2}$ index statistic. When $p>0.1$ and $\mathrm{I}^{2}<50 \%$, fixed-effect models were applied for the calculation of pooled effect index and only if $p<0.1$ and $\mathrm{I}^{2}>50 \%$, the random-effect models were used. A comparative analysis of the PSM rates was performed by stratifying selection balance as a subgroup.

\section{Results}

This review was performed according to the Preferred Reporting Items of Systematic Reviews and Meta-analysis (PRISMA) statement. A total of 117 records were retrieved after electronic search strategy, which ultimately included 21 studies [6, 11-30]. Figure 1 present the PRISMA flowchart of literature searches and Table 3 provided detailed characteristics of the included studies. Among the 21 studies included, 15 were controlled studies and 6 were surgical series. Eight trials paralleling conventional interfascial technique as controlled groups were included for comparative meta-analysis. Additional file 1: Table S1 showed the risk of bias in individual studies.

\section{One-arm meta-analysis}

Figure 2 summarized the prevalence of total PSMs recorded in the intrafascial group of the published surgical series or controlled studies. The total PSM rate ranged from 2.2 to $35 \%$, with a pooled rate of $14.2 \%$ (498/3351, $95 \%$ confidence interval $[\mathrm{CI}]: 11.0-17.3 \%)$. It was possible to calculate the heterogeneity among the included studies as $\mathrm{I}^{2}$ was $86.38 \%$. Three studies showed significantly higher PSM rates than the pooled rate, which included the studies of Curto 2006 [11], Choi 2012 [18], and Mortezavi 2012 [16], with a PSM rate of $30.8 \%$ (127/413, 95\% CI: 26.3-35.2\%), 34\% (17/50, 95\% CI: 20.9-47.1\%), and 35\% (28/80, 95\% CI: $24.5-45.5 \%)$, respectively, whereas the VIP team reported a notably lower PSM rate of $1 / 46$ [27]. No obvious differences could be detected among the 3 surgery types of LRP, RRP, and RALRP. PSM rates of intrafascial group stratified by pathological tumor stages could be found in Additional files 2 and 3, which showed that the pooled PSM rate was $9.7 \%(236 / 2423,95 \%$ CI: $7.0-12.4 \%)$ in pT2 cancers (Additional file 2: Figure S1) and 44.0\% (208/527, 95\% CI: 34.9-53.2\%) in pT3 cancer (Additional file 3: Figure S2). Overlapping higher rates could be seen in terms of the PSM rate in pT2 cancer that the studies of Curto (2006) [11] and Mortezavi (2012) [16], 


\section{PRISMA 2009 Flow Diagram}

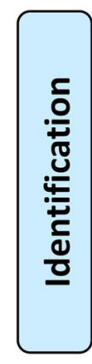

Records identified through

database searching

( $n=117$ )

Additional records identified through other sources

$(n=0)$

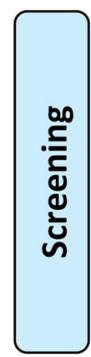

Records after duplicates removed

$(n=117)$
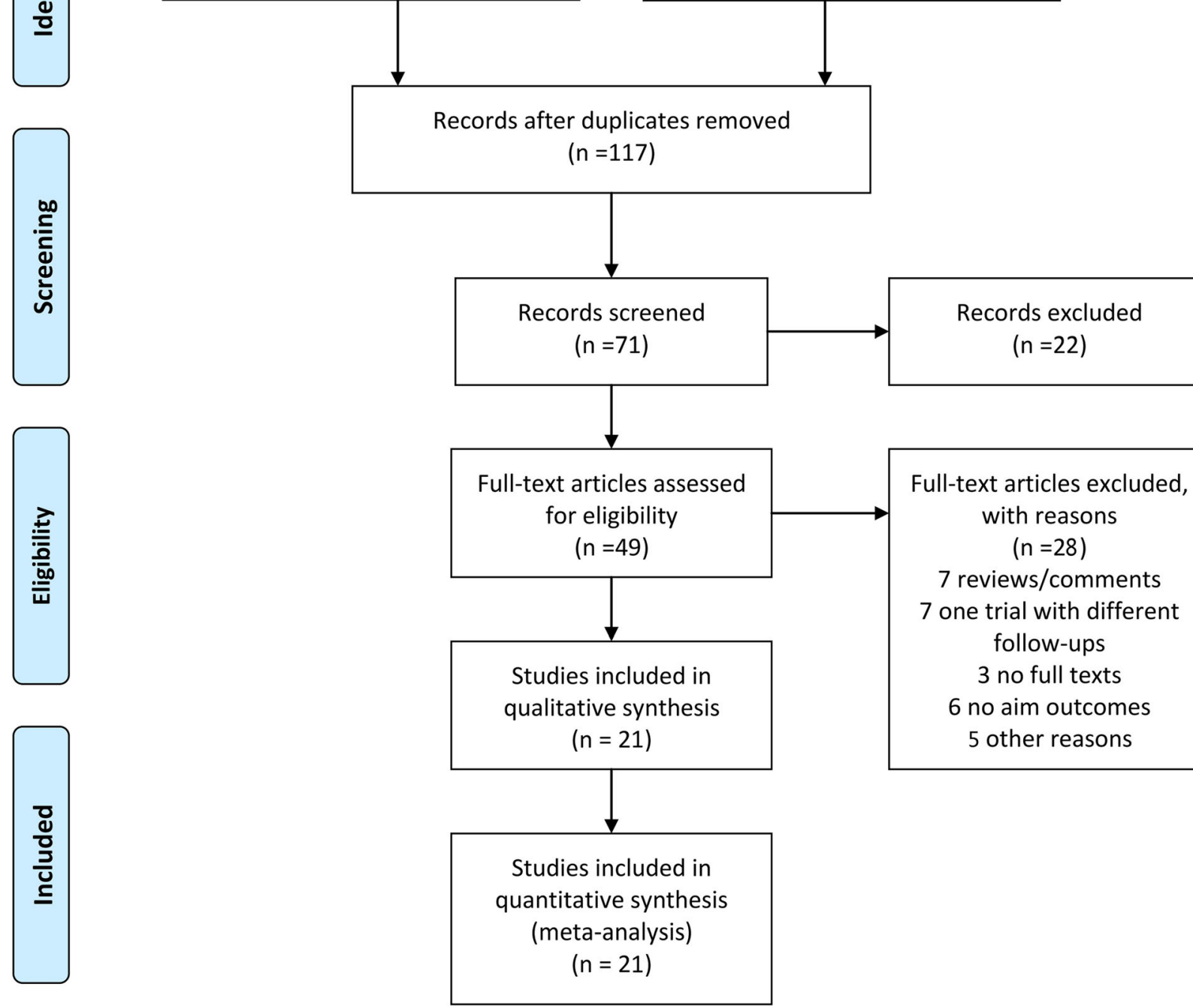

Fig. 1 PRISMA flowchart for identification and selection of studies for this systematic review

which also reported a significantly higher PSM rate than the pooled rate; however, this overlap was not observed with regard to the PSM rate in pT3 cancer.

\section{Meta-regression analysis}

Table 4 summarized the result of meta-regression evaluating the impact of confounding factors affecting PSM rates. Age, pT2 cancer percentage, and SSOS were significantly associated with the total PSM rate, and age was the only factor that affected the PSM rate in pT3 cancer. Regarding the total PSM rate, the regression model demonstrated that 1 more year to the mean age could increase the total PSM rate by an average of $1.2 \%$, while each 1 point of SSOS could decrease it by an average of $1.3 \%$. Moreover, preservation techniques including D-fascia preservation, puboprostatic ligament sparing, selective ligation of DVC, 
Table $\mathbf{3}$ Characteristics of the included studies in meta-analysis

\begin{tabular}{|c|c|c|c|c|c|c|}
\hline First author & Study design & Country & Surgery duration & Sample size for Intra-RP & Surgical type & Mean age in Intra-RP \\
\hline Curto 2006 & surgical series & France & 2003.5-2005.3 & 425 & LRP & 62.0 \\
\hline Budaus 2009 & surgical series & Germany & 2005.4-2007.12 & 1150 & RRP & 63 \\
\hline Stolzenburg 2008 & surgical series & Germany & 2001.12-2007.11 & 150 & LRP & 60.2 \\
\hline Xylinas 2010 & surgical series & France & 2007.12-2008.6 & 50 & RALRP & 60.8 \\
\hline Asimakopoulos 2010 & surgical series & Italy & 2007.10-2009.3 & 30 & RALRP & 52 \\
\hline Khoder 2012 & surgical series & Germany & 2007.1-2009.12 & 231 & RRP & 63.3 \\
\hline Greco 2010 & controlled & Germany & $2005.1-2007.11$ & 300 & LRP vs RRP & 61 \\
\hline Greco 2011 & controlled & Germany & 2005.1-2009.5 & 250 & LRP & 59 \\
\hline Asimakopoulos 2011 & randomized controlled & Italy & 2007.10-2008.10 & 128 & LRP vs RALRP & 60.4 \\
\hline Hoshi 2013 & controlled & Japan & 2009.1-2011.10 & 44 & LRP & 65.7 \\
\hline Stewart 2011 & controlled & UK & 2006.2-2009.12 & 102 & LRP & 61.5 \\
\hline Mortezavi 2012 & controlled & Switzerland & 2006.5-2008.8 & 80 & RALRP & \\
\hline VIP 2005 & controlled & USA & 2003.1-2003.12 & 35 & RALRP & 58.6 \\
\hline Neil 2009 & controlled & UK & 2000.3-2007.10 & 240 & LRP & 59 \\
\hline Potdevin 2009 & controlled & New Jersey & $2006.1-2007.12$ & 70 & RALRP & 58.63 \\
\hline Stolzenburg 2010 & randomized controlled & Germany & 2004.6-2008.6 & 200 & LRP & 61 \\
\hline Choi 2012 & controlled & Korea & 2011.11-2012.4 & 50 & LRP & 66.5 \\
\hline Ihsan-Tasci 2015 & controlled & Turkey & 2009.8-2012.12 & 200 & RALRP & 60.8 \\
\hline
\end{tabular}

Intra-RP intrafascial radical prostatectomy, VIP Vattikuti Institute Prostatectomy, RRP retropubic radical prostatectomy, $L R P$ laparoscopic radical prostatectomy, $R A L R P$ robot-assisted laparoscopic radical prostatectomy

had no significant influence on PSM rate. Figure 3 depicted the meta-regression plot to describe the effect of the confounding factors of patient age, pT2 cancer percentage, and SSOS score on total PSM rate.

\section{Comparative meta-analysis}

As shown in Figs. 4 and 5, the $\mathrm{I}^{2}$ standing for heterogeneity among the studies was 39,47 , and $0 \%$ in the meta-analysis of total PSM rate, PSM rate in pT2 cancer, and PSM rate in pT3 cancer, respectively, therefore, fixed-effects models were applied. None of the 3 meta-analyses demonstrated a significant difference between the intra- and interfascial groups. It is noteworthy that, in the meta-analysis of total PSM rate (Fig. 4) and PSM rate in pT2 cancer (Fig. 5a), under a balanced selection of preoperative oncologic risk, the interfascial group had a numerically lower rate compared with the intrafascial group, but interestingly, pooling the studies without a balanced baseline resulted in an observable significant difference in PSM rate in favor of the intrafascial group. This condition was not observed in the assessment of the PSM rate in pT3 (Fig. 5b), which showed consistency between the balanced and imbalanced studies, both indicating that the intrafascial group was associated with a higher PSM rate, although insignificant statistically. Table 5 provided characteristics of studies included in comparable meta-analysis reporting
PSM and Additional file 4: Figure S3 showed the funnel plots for assessing the publication biases.

\section{Discussion}

In this study we conducted a systematic review and pooled analysis of oncological outcomes following intrafascial nerve-sparing prostatectomy. In 2012, a detailed and in-depth systematic review summarizing all surgical series of RALP between 2008 to 2011 was reported by Novara et al. [31], wherein they indicated that the prevalence of PSM after RALP was, on average, $15 \%$ in all-stage disease and $9 \%$ in pathologically localized cancer; PSM rates were similar following RARP, RRP, and LRP. The authors proposed an average PSM rate of 15 and $10 \%$ could be expected for all-stage and pT2 cancers after RALP, respectively. In this present meta-analysis, we found that the pooled PSM rate in the intrafascial group was, overall, $14.2 \%$ in all stages of prostate cancer and $9.7 \%$ in pT2 disease regardless of surgery types, which seemed to match the results of previous review. Comparative analysis revealed no significant difference in PSM rate between the intra- and inter-fascial groups, which was consistent with a previous meta-analysis [32]. From this point of view, oncological outcomes of intrafascial technique seemed acceptable, or at least not worse than with conventional approach. However, a hasty conclusion of the oncological safety of this 


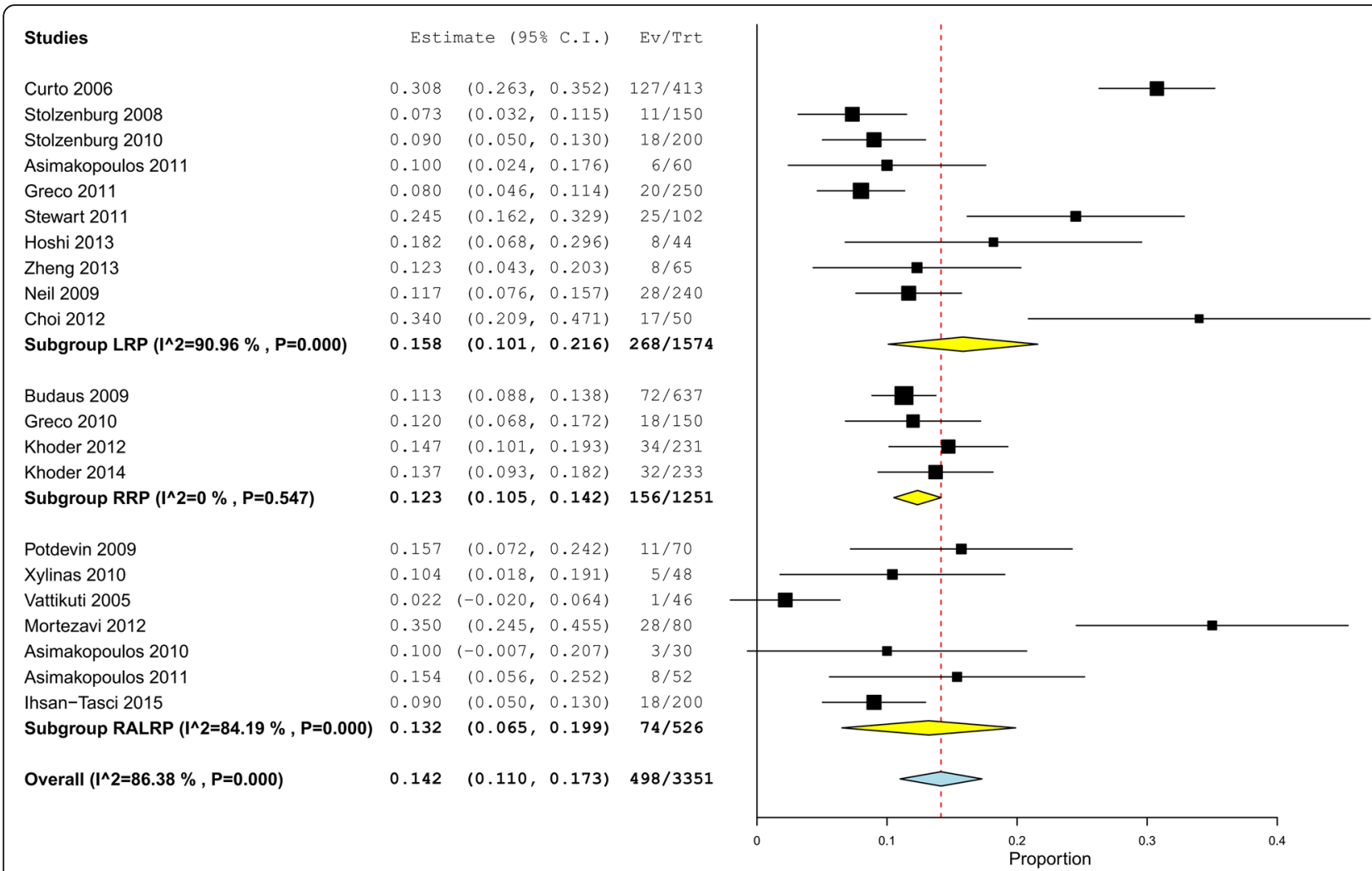

Fig. 2 Forest plot for one-arm meta-analysis of studies adopting the intrafascial technique in terms of total PSM rate in all-stage disease stratified by surgical types. PSM, positive surgical margin; LRP, laparoscopic radical prostatectomy; RRP, retropubic radical prostatectomy; RALRP, robotassisted laparoscopic radical prostatectomy; VIP, Vattikuti Institute Prostatectomy

technique should be avoided, as there are additional issues worthy of critical appraisal.

Extracapsular extension of carcinoma could lead to higher PSM rate of radical prostatectomy compared with that associated with a localized tumor. The mean percentage of pT2 cancer in the intrafascial studies included in our present review was $84.5 \%$ (range: 58.6-98.1\%), which is significantly higher than that in the 17 surgical series included in Novara's review [31] (t-test of independent samples: mean difference $=-7.91569, \mathrm{t}=-$ 2.618, $p=.014$ ); this meant, surgeons selected more patients with localized disease to perform intrafascial approach, but only comparable total PSM rates were gained. Moreover, according to the guidelines of the European Association of Urology, radical prostatectomy could be extended for indications such as patients with intermediate-risk, localized prostate cancer with clinical stage T2b-T2c, Gleason score $=7$, or PSA $10-20 \mathrm{ng} / \mathrm{ml}$

Table 4 Meta-regression models evaluating the influence of the confounded factors to the PSM rate

\begin{tabular}{|c|c|c|c|c|c|c|c|c|c|c|c|c|}
\hline \multirow[t]{2}{*}{ Factor } & \multicolumn{2}{|l|}{ Age } & \multicolumn{2}{|c|}{ D-fascia preservation } & \multicolumn{2}{|c|}{$\begin{array}{l}\text { Puboprostatic } \\
\text { ligament sparing }\end{array}$} & \multicolumn{2}{|c|}{$\begin{array}{l}\text { Selective/no } \\
\text { ligation of DVC }\end{array}$} & \multicolumn{2}{|c|}{ pT2 cancer percent } & \multicolumn{2}{|c|}{$\begin{array}{l}\text { Selection Score } \\
\text { of Oncologic } \\
\text { Safety }\end{array}$} \\
\hline & $\beta \pm S E$ & $P$-value & $\beta \pm S E$ & P-value & $\beta \pm S E$ & P-value & $\beta \pm S E$ & $P$-value & $\beta \pm S E$ & P-value & $\beta \pm S E$ & P-value \\
\hline $\begin{array}{l}\text { Total PSM rate } \\
\text { in all-stage }\end{array}$ & $\begin{array}{l}0.013 \\
\pm 0.006\end{array}$ & 0.044 & $\begin{array}{l}-0.032 \\
\pm 0.037\end{array}$ & 0.385 & $\begin{array}{l}-0.022 \\
\pm 0.039\end{array}$ & 0.561 & $\begin{array}{l}0.021 \\
\pm 0.045\end{array}$ & 0.643 & $\begin{array}{l}-0.004 \\
\pm 0.002\end{array}$ & 0.012 & $\begin{array}{l}-0.013 \\
\pm 0.005\end{array}$ & 0.012 \\
\hline $\begin{array}{l}\text { PSM rate in } \\
\text { pT2 cancer }\end{array}$ & $\begin{array}{l}0.005 \\
\pm 0.005\end{array}$ & 0.303 & $\begin{array}{l}0.011 \\
\pm 0.032\end{array}$ & 0.727 & $\begin{array}{l}-0.050 \\
\pm 0.032\end{array}$ & 0.120 & $\begin{array}{l}-0.044 \\
\pm 0.033\end{array}$ & 0.183 & - & - & - & - \\
\hline $\begin{array}{l}\text { PSM rate in } \\
\text { pT3 cancer }\end{array}$ & $\begin{array}{l}0.041 \\
\pm 0.018\end{array}$ & 0.025 & $\begin{array}{l}-0.001 \\
\pm 0.097\end{array}$ & 0.990 & $\begin{array}{l}0.111 \\
\pm 0.075\end{array}$ & 0.139 & $\begin{array}{l}-0.111 \\
\pm 0.074\end{array}$ & 0.133 & - & - & - & - \\
\hline
\end{tabular}

Each of the confounded factors including patients' age, preservation technique(D-fascia preservation, puboprostatic ligament sparing and selective/no ligation of DVC) was included respectively in the meta-regression models to assess the influence of the confounded factors to the PSM rate. If $p$-value was less than 0.05 , the cofficient and $p$-value were showed as boldface in the table. D-fascia Denonvilliers fascia, DVC dorsal venous complex, PSM positive surgical margin, $\beta$ coefficient, SE standard error 


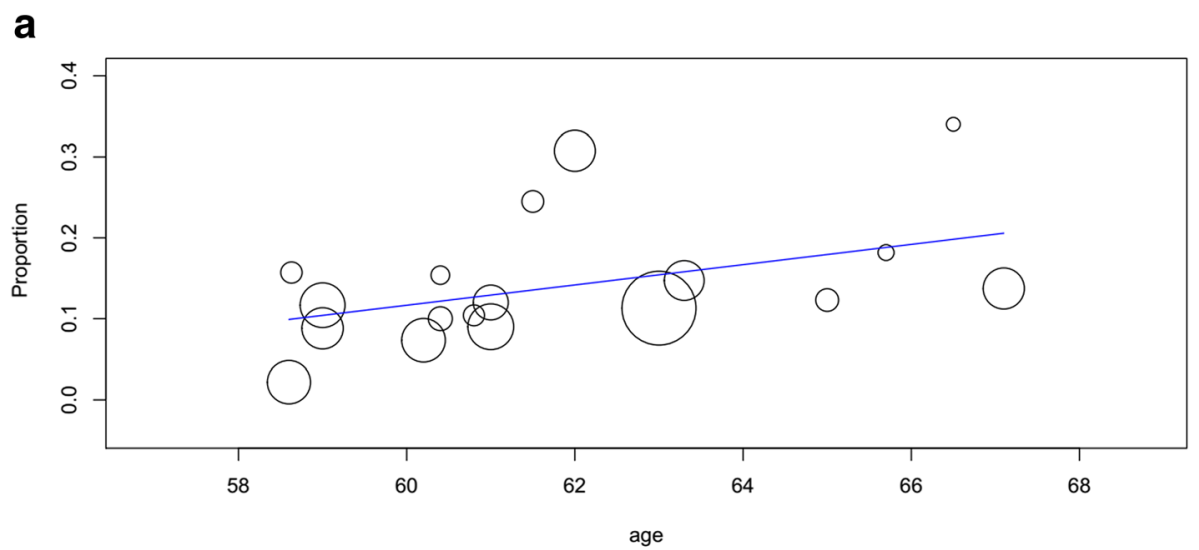

b

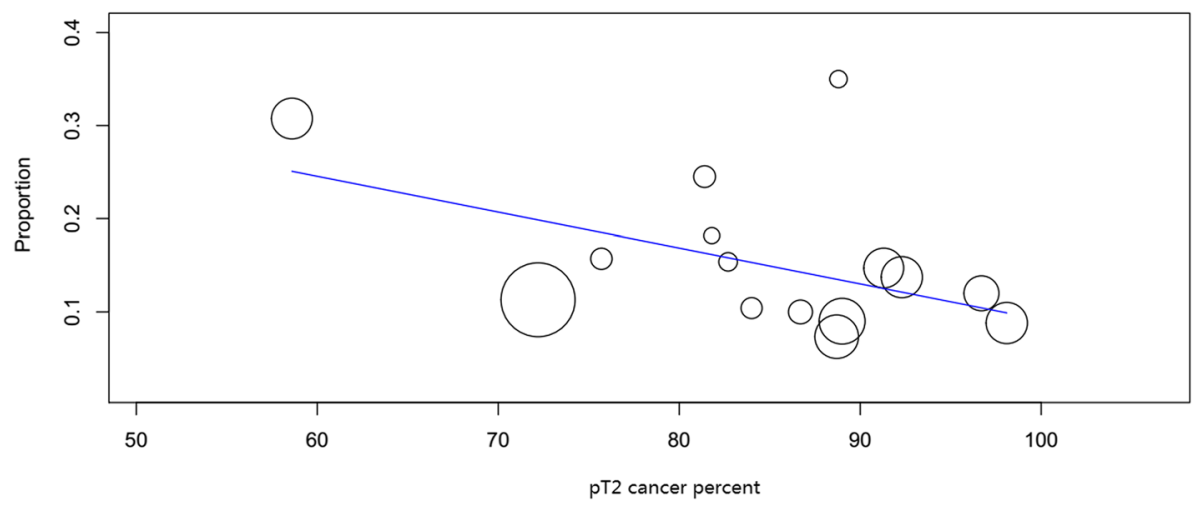

C

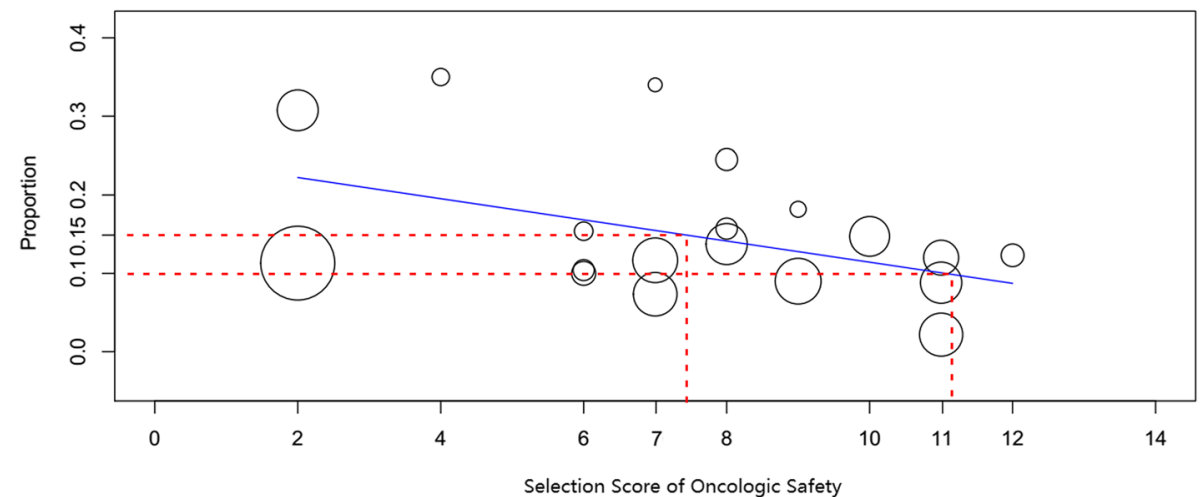

Fig. 3 Influence of (a) age, (b) pT2 cancer percentage, and (c) the Selection Score of Oncologic Safety on total PSM rate in all-stage cancer following intrafascial radical prostatectomy. PSM, positive surgical margin

[3]. However, our review found that most surgeons applied more rigorous selection criteria against generally recommended indications for radical prostatectomy. For example, the VIP team in 2005 reported a notably low PSM rate with a robot-assisted surgical system wherein only 1 case of positive margin was detected from among 46 patients who underwent intrafascial RALRP [27]. With regard to their selection criteria, only patients with clinical T1c stage cancer combined with a Gleason score $\leq 6$ and preoperative PSA $\leq 10$ were selected for the adoption of the intrafascial technique. Therefore, the currently acceptable low PSM rate following intrafascial prostatectomy could be attributed to more stringent patient selection and, subsequently, a higher proportion of localized disease; however, the oncological safety of this technique could not be confirmed. If intrafascial dissection is carried out among patients with a high risk of extracapsular invasion, the result may be unsatisfactory. For example, in 2006, Curto et al. reported a contemporary laparoscopic surgical series wherein a surgical team 


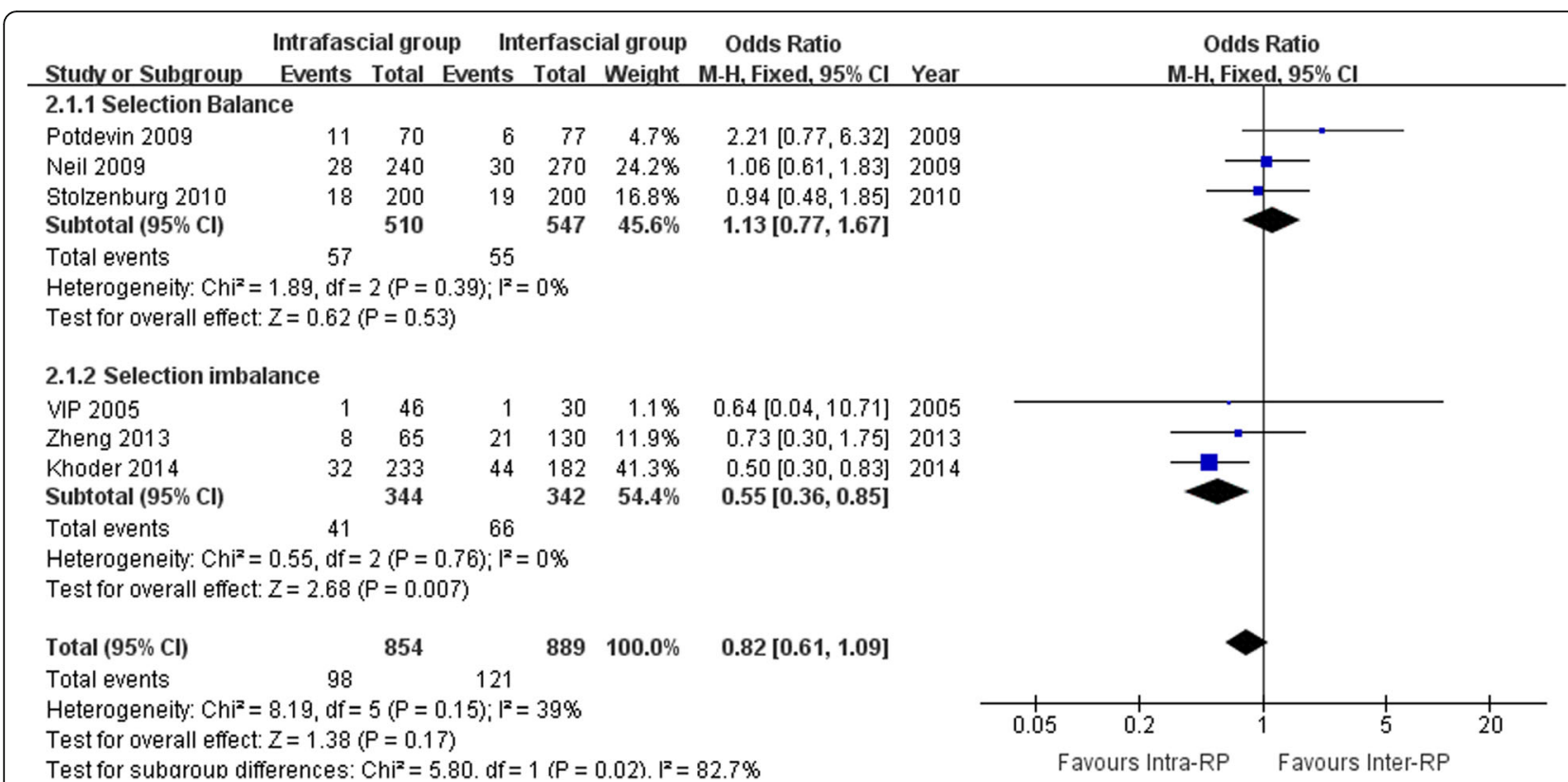

Fig. 4 Forest plots for comparative meta-analysis of studies comparing the intrafascial with the interfascial technique in terms of the total PSM rate in all-stage cancer stratified by whether selection balance was achieved. PSM, positive surgical margin; VIP, Vattikuti Institute Prostatectomy

experienced in over 2800 LRP performed intrafascial prostatectomies in patients with organ-confined prostate cancer (including 3 cases of cT3a disease) without other selection restrictions such as PSA level or Gleason score, for control of preoperative oncological risk. Subsequently, the percentage of pT2 cancer was only $58.6 \%$ and the overall PSM rate in all-stage tumors was as high as $30.7 \%(127 / 413)$ [11].

With regard to our regression model, the percentage of pT2 cancer was significantly associated with the total PSM rate, and high proportion of pT2 disease led to a low PSM rate. However, as preoperative pathological staging could not be obtained, the risk of extracapsular invasion was predicted on the basis of the patient's preoperative information. Clinical stage, PSA level, Gleason score, and positive biopsy cores could be used as independent predictors of this risk and, therefore, we scored each factor and summed to SSOS to quantitatively evaluate this risk preoperatively. We identified a significant correlation between the SSOS and pathological pT2 percentage (Pearson Correlation $=0.749, p$ $=.001$ ). Moreover, an obvious association could be identified from our meta-regression model by including SSOS as a confounding factor, indicating that, for intrafascial prostatectomy, stringent case selection was associated with low risk of PSM and quantitatively, each 1 point of SSOS could decrease the total PSM rate by $1.3 \%$ on average. Thus, based on our regression model, the preoperative SSOS should be more than 7 points to obtain a postoperative PSM rate of $15 \%$ on average and SSOS more than 11 points meant a postoperative PSM rate of $10 \%$. Surgeons intending to adapt this technique should take cautions when setting criteria for patient selection and we, for the first time, proposed the SSOS as an indication of intrafascial prostatectomy.

SSOS had four components, by which we used to evaluate the patients' selection criteria for intrafascial prostatectomy of the included studies. We performed in-depth regression analysis setting total PSM rates as dependent variable by including each section and excluding each section from SSOS (see Additional file 5: Table S2). The result showed that section 1 (clinical $\mathrm{T}$ stage) was the most influential factor, as only section 1 could significantly affect PSM rates and when excluding section 1, the regression model became insignificant. Thus surgeons should make clinical $\mathrm{T}$ stage a priority when using SSOS as an indication.

A histological study by the VIP team indicated that $2 / 30$ anterolateral zones of the prostate specimen after the Veil technique revealed capsular incision, compared with $0 / 40$ for the standard technique [33]. In pathologically localized disease, the tumor does not invade beyond the limit of the prostatic capsule; thus, only intracapsular incision will lead to positive margins. Theoretically, intrafascial dissection should increase risk of capsular incision compared with the interfascial technique and, subsequently, with a localized tumor situated close to the capsule or having large volume, is likely to lead to PSM. This can be inferred from Curto's surgical series [11], wherein investigators found a higher PSM rate, especially for pT2c tumors, as compared with the previous largest series; however, this difference was not present for other pathological stages. 


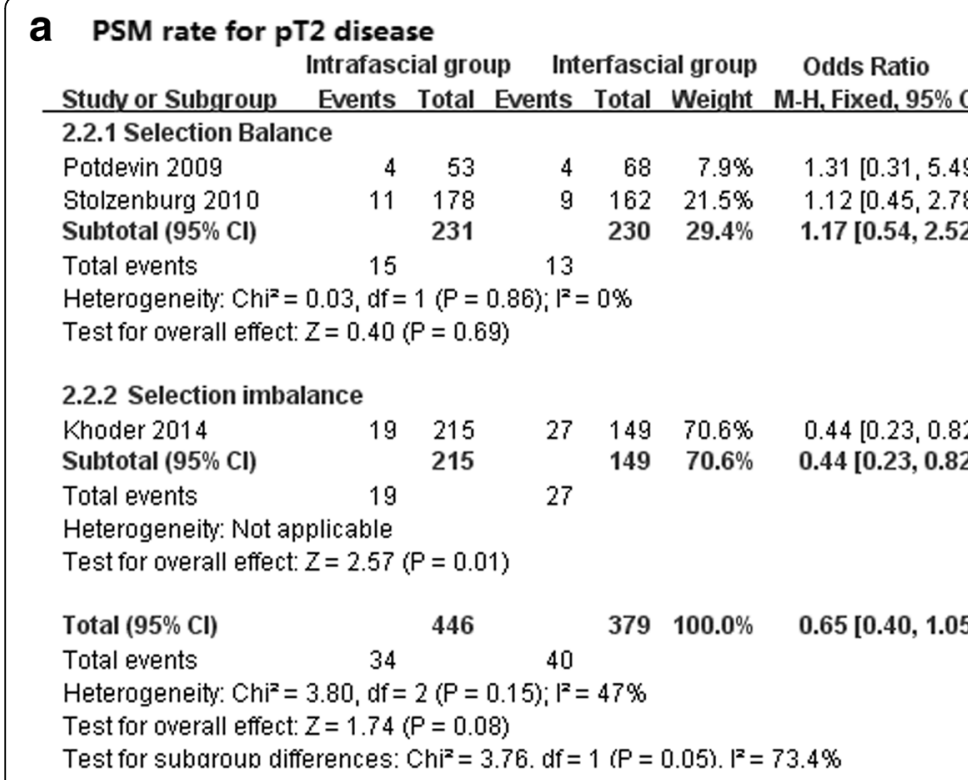

\section{b PSM rate for PT3 disease}

\begin{tabular}{|c|c|c|c|c|c|c|c|c|c|c|c|}
\hline \multirow[b]{2}{*}{ Study or Subgroup } & \multicolumn{2}{|c|}{ Intrafascial group } & \multicolumn{3}{|c|}{ Interfascial group } & \multirow{2}{*}{$\begin{array}{c}\text { Odds Ratio } \\
\text { M-H. Fixed, } 95 \% \mathrm{Cl}\end{array}$} & \multirow{2}{*}{\multicolumn{5}{|c|}{$\begin{array}{c}\text { Odds Ratio } \\
\text { M-H, Fixed, 95\% Cl }\end{array}$}} \\
\hline & Events & Total Ev & nts & otal & Weight & & & & & & \\
\hline \multicolumn{12}{|c|}{ 2.3.1 Selection Balance } \\
\hline Potdevin 2009 & 7 & 17 & 2 & 9 & $15.6 \%$ & $2.45[0.39,15.50]$ & & & & & \\
\hline Stolzenburg 2010 & 7 & 22 & 10 & 38 & $50.6 \%$ & $1.31[0.41,4.13]$ & & & & & \\
\hline Subtotal $(95 \% \mathrm{Cl})$ & & 39 & & 47 & $66.2 \%$ & $1.58[0.60,4.13]$ & & & & & \\
\hline Total events & 14 & & 12 & & & & & & & & \\
\hline \multirow{2}{*}{\multicolumn{12}{|c|}{ Heterogeneity: $\mathrm{Chi}^{2}=0.32, \mathrm{df}=1(\mathrm{P}=0.57) ;\left.\right|^{2}=0 \%$}} \\
\hline & & & & & & & & & & & \\
\hline \multicolumn{12}{|c|}{ 2.3.2 Selection imbalance } \\
\hline Khoder 2014 & 13 & 18 & 17 & 33 & $33.8 \%$ & $2.45[0.71,8.43]$ & & & & & \\
\hline Subtotal $(95 \% \mathrm{Cl})$ & & 18 & & 33 & $33.8 \%$ & $2.45[0.71,8.43]$ & & & & & \\
\hline Total events & 13 & & 17 & & & & & & & & \\
\hline \multicolumn{12}{|c|}{ Heterogeneity: Not applicable } \\
\hline \multicolumn{12}{|c|}{ Test for overall effect: $Z=1.42(P=0.16)$} \\
\hline Total $(95 \% \mathrm{Cl})$ & & 57 & & 80 & $100.0 \%$ & $1.87[0.88,3.98]$ & & & & & \\
\hline Total events & 27 & & 29 & & & & & & & & \\
\hline \multicolumn{7}{|c|}{$\begin{array}{l}\text { Heterogeneity: } \mathrm{Chi}^{2}=0.64, \mathrm{df}=2(\mathrm{P}=0.73) ; \mathrm{I}^{2}=0 \% \\
\text { Test for owerall effect } Z=1.62(\mathrm{P}=0.10)\end{array}$} & $0.1 \quad 0.2$ & 0.5 & 1 & 5 & 10 \\
\hline \multicolumn{7}{|c|}{$\begin{array}{l}\text { Test for overall effect: } Z=1.62(P=0.10) \\
\text { Test for subaroun differences: } \mathrm{Chi}^{2}=0.30\end{array}$} & Favoul & ntra-RP & Favour: & ter-RP & \\
\hline
\end{tabular}

Fig. 5 Forest plots for comparative meta-analysis of studies comparing the intrafascial with interfascial technique in terms of (a) PSM rate for pT2 cancer and (b) PSM rate for PT3 cancer stratified by whether selection balance was achieved. PSM, positive surgical margin

For comparative analysis, we only included parallel-group studies including conventional interfascial nerve-sparing prostatectomy as the control. Several studies compared the outcomes of intrafascial prostatectomy with that of wide dissection or non-nerve-sparing prostatectomy, but as reported in some of these studies, wider preservation of the NVBs may be associated with a higher risk of PSM $[34,35]$. Thus, for these studies, the oncological results could be confounded by the nerve-sparing technique, and, therefore, we did not include these studies in the comparative analysis. In our meta-analysis comparing intra- and interfascial groups, we stratified studies according to patient selection balance; however, the overall pooled result demonstrated there was no significant difference for PSM rate in all pathological stages of disease. Notably, in the study by Khoder et al. [12], patients were selected to undergo intrafascial prostatectomy only if biopsy Gleason scores were $\leq 6$ and PSA $\leq 10 \mathrm{ng} / \mathrm{mL}$ with low tumor size; patients with relatively higher Gleason scores and PSA levels were allocated to the interfascial group, and this was considered as selection imbalance. These researchers ultimately reported that PSM rates for pT2 stage and all pathological stages were lower in the intrafascial group compared with the interfascial group; however, this advantage was not reported for pT3 cancer. From the subgroup results in our comparative analysis, a significantly lower PSM rate was 
Table 5 Characteristics of studies included in comparable meta-analysis reporting PSM rate

\begin{tabular}{|c|c|c|c|c|c|c|c|c|}
\hline \multirow[t]{2}{*}{ First author } & \multirow[t]{2}{*}{$\begin{array}{l}\text { Selection } \\
\text { balance }\end{array}$} & \multirow[t]{2}{*}{ Criteria for Intra-RP } & \multirow[t]{2}{*}{ Criteria for Inter-RP } & \multirow[t]{2}{*}{$\begin{array}{l}\text { SSOS for } \\
\text { Intra-RP }\end{array}$} & \multirow[t]{2}{*}{$\begin{array}{l}\text { Percent of pT2 } \\
\text { cancer, \% (Intra-RP } \\
\text { vs Inter-RP) }\end{array}$} & \multicolumn{3}{|c|}{$\begin{array}{l}\text { PSM rate, \% } \\
\text { (Intra-RP vs } \\
\text { Inter-RP) }\end{array}$} \\
\hline & & & & & & pT2 & pT3 & all-stage \\
\hline VIP 2005 & $\mathrm{~N}$ & $\begin{array}{l}\mathrm{CT} 1 \mathrm{c} \text { and } \mathrm{PSA} \leq 10 \text { and Gleason } \\
\text { score } \leq 6\end{array}$ & $\begin{array}{l}\text { CT2a/b or PSA }>10 \leq 20 \text { or } \\
\text { Gleason score }=7\end{array}$ & 11 & & & & $2.2: 3.3$ \\
\hline Zheng 2013 & $\mathrm{~N}$ & $\begin{array}{l}\mathrm{CT} 1 / 2 \mathrm{a} \text { and } \mathrm{PSA} \leq 10 \text { and Gleason } \\
\text { score } \leq 3+4 \text { and positive } \\
\text { cores } \leq 3 / 12\end{array}$ & $\begin{array}{l}\text { CT2b/c or positive cores }>3 / 12 \\
\text { and PSA } \leq 10 \text { and Gleason } \\
\text { score } \leq 3+4\end{array}$ & 12 & & & & $\begin{array}{l}\text { 12.3: } \\
16.2\end{array}$ \\
\hline Khoder 2014 & $\mathrm{~N}$ & $\begin{array}{l}\mathrm{CT} 1 / 2 \text { and PSA } \leq 10 \text { and Gleason } \\
\text { score } \leq 6\end{array}$ & $\begin{array}{l}\mathrm{CT} 1 / 2 \text { and PSA } \leq 15 \text { and Gleason } \\
\text { score } \leq 7\end{array}$ & 8 & 92.3: 81.9 & $\begin{array}{l}\text { 8.8: } \\
18.1\end{array}$ & $\begin{array}{l}72.2: \\
51.5\end{array}$ & $\begin{array}{l}13.7: \\
24.2\end{array}$ \\
\hline Potdevin 2009 & Y & $\begin{array}{l}\text { CT1/2a and PSA } \leq 10 \text { and Gleason } \\
\text { score } \leq 7\end{array}$ & & 8 & 75.7: 88.3 & $\begin{array}{l}7.5: \\
5.9\end{array}$ & $\begin{array}{l}41.2: \\
22.2\end{array}$ & 15.7: 7.8 \\
\hline Neil 2009 & Y & $\begin{array}{l}\mathrm{CT} 1 / 2 \text { and } \mathrm{PSA} \leq 10 \text { and absence of } \\
\text { primary Gleason pattern } 4 / 5\end{array}$ & & 7 & & & & $\begin{array}{l}11.7: \\
11.1\end{array}$ \\
\hline $\begin{array}{l}\text { Stolzenburg } \\
2010\end{array}$ & Y & $\begin{array}{l}\mathrm{CT} 1 / 2 \mathrm{a} \text { and } \mathrm{PSA}<10 \text { and Gleason } \\
\text { score } \leq 3+4\end{array}$ & & 9 & 89: 81 & $\begin{array}{l}6.2: \\
5.6\end{array}$ & $\begin{array}{l}31.8: \\
26.3\end{array}$ & 9.0: 9.5 \\
\hline
\end{tabular}

Intra-RP intrafascial radical prostatectomy, Inter-RP interfascial radical prostatectomy, SSOS Selection Score of Oncologic Safety, VIP Vattikuti Institute Prostatectomy, $Y$ yes, $N$ no.

identified in favor of the intrafascial technique in pT2 and all-stage disease for pooled studies with non-balanced selection criteria. All of these non-balanced studies applied additional more stringent patient selection criteria for the intrafascial technique, as compared with patient selection for the interfascial group. With regard to subgroup analysis of balanced studies, pooled results revealed a higher PSM rate, although statistically non-significant, with the intrafascial technique for $\mathrm{pT} 2$ and all-stage cancers. The variance between subgroups of balanced and non-balanced studies reconfirmed the crucial role of patient selection in controlling the PSM rate. In pT3 cancer, a higher PSM rate, although statistically non-significant, was detected for the interfascial group and may be attributable to insufficient sample size.

The PSM rate is known to be associated with surgeon-related characteristics, with surgical experience being the most important factor. Surgeons experienced in high-volume resections could decrease the PSM rate [36, 37]. A study evaluating the learning curve of radical prostatectomy indicated that increasing surgical experience was associated with substantial reductions in cancer recurrence: however, for LRP, the learning curve was slower than for RRP [38]. The relatively high PSM rate for LRP reported by Choi et al. in 2012 can be attributed to the learning curve [18]. In fact, the authors emphasized that, in the first 30 cases, the PSM rate was $51.7 \%$, and then subsequently decreased to $9.5 \%$. However, there are no published studies reporting an evaluation of PSM with the learning curve of the intrafascial technique.

Regarding on the dissection plane during procedure, surgeons supplied several technical variations, including VIP technique and Leipzig technique. We included all the intrafascial surgeries in this pooled study regardless of the variable techniques. Most authors described their dissection technique in the original manuscripts, but ignored pathological evaluation of the specimen regarding whether the utilized surgical technique was intra or interfacial nerve sparing. Thus we can only judge the classification depending on the authors' description. As the PSM rates were affected by the dissection plane, the quality of the original trials may confound our conclusion and this is a major limitation when we included these trials in our pooled analysis.

In the present review, no obvious evidence indicative of preserving technique, including $\mathrm{D}$-fascia preservation, puboprostatic ligament sparing, or selective/no ligation of DVC, was detected in conjunction with increased PSM rate. In a retrospective controlled study reported by Hoshi et al. in 2013 [15], the authors reconfirmed that the DVC preserving technique would not increase the PSM rate, as compared with the conventional intrafascial technique. Further, we could not conclusively determine any significant differences among the 3 surgical types of RRP, LRP, and RALRP from our pooled results. Overlapping results could be identified from the studies of Asimakopoulos and Greco. Asimakopoulos et al. conducted a randomized comparison between LRP and RALRP and found no statistically significant differences for the PSM rate [21]. In the study of Greco et al. comparing RRP with LRP, results demonstrated that both surgical types had similar PSM rates [24]. In terms of our regression model, age was another relevant predictor of the PSM rate, demonstrating that older patients had higher PSM rates for pT3 and all-stage cancers.

\section{Conclusions}

In summary, intrafascial technique resulted in a total PSM rate of $14.2 \%$ for all-stage cancer and $9.7 \%$ in pT2 
disease. With stringent case selection and conducted by experienced surgeons, intrafascial prostatectomy could offer an acceptable or, at least, equivalent PSM rate compared with the conventional interfascial approach. Current patient selection criteria are more stringent than those indicated for radical prostatectomy by guidelines, and we proposed SSOS as an indication of intrafascial prostatectomy. Preoperative SSOS should be more than 7 points to obtain an acceptable postoperative PSM rate of $15 \%$ on average.

\section{Additional files}

Additional file 1: Table S1. Risk of bias summary of included controlled studies. Review authors' judgments about each risk of bias item for included study. (DOCX 16 kb)

Additional file 2: Figure S1. Forest plots for one-arm meta-analysis of studies adopting the intrafascial technique in terms of PSM rate in PT2 disease stratified by surgical types. PSM, positive surgical margin; LRP, laparoscopic radical prostatectomy; RRP, retropubic radical prostatectomy; RALRP, robot-assisted laparoscopic radical prostatectomy. (TIF 2042 kb)

Additional file 3: Figure S2. Forest plots for one-arm meta-analysis of studies adopting the intrafascial technique in terms of PSM rate in PT3 disease stratified by surgical types. PSM, positive surgical margin; LRP, laparoscopic radical prostatectomy; RRP, retropubic radical prostatectomy; RALRP, robot-assisted laparoscopic radical prostatectomy. (TIF 1933 kb)

Additional file 4: Figure S3. Funnel plots for assessing publication biases of comparative meta-analysis of (a) total PSM rate, (b) PSM rate for PT2 disease and (c) PSM rate for PT3 disease. (TIF $5431 \mathrm{~kb}$ )

Additional file 5: Table S2. Meta-regression models evaluating each section of SSOS to the PSM rate. (DOCX $14 \mathrm{~kb}$ )

\section{Abbreviations \\ D-fascia: Denonvilliers fascia; DVC: Dorsal venous complex; LRP: Laparoscopic radical prostatectomy; NS: Not evaluated; OR: Odds ratio; PICOS: Patients, intervention, comparison, outcomes, and study design; PRISMA: Preferred reporting items of systematic reviews and meta-analysis; PSA: Prostate- specific antigen; PSMs: Positive surgical margins; RALRP: Robot-assisted laparoscopic radical prostatectomy; RRP: Retropubic radical prostatectomy; SSOS: Selection score of oncologic safety; VIP: Vattikuti Institute Prostatectomy}

\section{Acknowledgements}

Not applicable.

\section{Funding}

XW and XHL were responsible for study conception and design, data collection and management. XHL was funded by Application and Basic Research Project Of Wuhan City (No.2015060101010049), Hubei Province Health and Family Planning Scientific Research Project (No.WJ2017M025 and No.WJ2017Z005), Natural Science Foundation of Hubei Province (No.2016CFB114) and Research Project of Wuhan University (No.2042017kf0097). XW was funded by Independent Research Project of Wuhan University (No. 1605/413000181).

No interferences occurred in carrying out the research project and in writing the manuscript that is the sole responsibility of the authors.

\section{Availability of data and materials}

All the data supporting our findings is contained in the manuscript.

\section{Authors' contributions}

XW and XHL: Study conception and design, data collection and management; JG, HC and XDW: data collection and analysis, preparation of figures and tables; XW and YQW: Writing and revision of the manuscript. All authors read and approved the final manuscript
Ethics approval and consent to participate

Not applicable.

\section{Consent for publication}

Not applicable.

\section{Competing interests}

The authors declare that they have no competing interests.

\section{Publisher's Note}

Springer Nature remains neutral with regard to jurisdictional claims in published maps and institutional affiliations.

Received: 17 November 2018 Accepted: 13 May 2019

Published online: 27 May 2019

\section{References}

1. Walsh PC. Radical prostatectomy for localized prostate cancer provides durable cancer control with excellent quality of life: a structured debate. J Urol. 2000;163(6):1802-7.

2. Han M, Partin AW, Pound CR, Epstein Jl, Walsh PC. Long-term biochemical disease-free and cancer-specific survival following anatomic radical retropubic prostatectomy. The 15-year Johns Hopkins experience. Urol Clin North Am. 2001;28(3):555-65.

3. Mottet N, Bellmunt J, Bolla M, Briers E, Cumberbatch MG, De Santis M, et al. EAU-ESTRO-SIOG guidelines on prostate Cancer. Part 1: screening, diagnosis, and local treatment with curative intent. Eur Urol. 2017;71(4):618-29.

4. Costello AJ, Brooks M, Cole OJ. Anatomical studies of the neurovascular bundle and cavernosal nerves. BJU Int. 2004;94(7):1071-6.

5. Stolzenburg JU, Rabenalt R, Tannapfel A, Liatsikos EN. Intrafascial nervesparing endoscopic extraperitoneal radical prostatectomy. Urology. 2006; 67(1):17-21

6. Budaus $L$, Isbarn $H$, Schlomm $T$, Heinzer $H$, Haese A, Steuber $T$, et al. Current technique of open intrafascial nerve-sparing retropubic prostatectomy. Eur Urol. 2009:56(2):317-24.

7. Rassweiler J. Intrafascial nerve-sparing laproscopic radical prostatectomy: do we really preserve relevant nerve-fibres? Eur Urol. 2006:49(6):955-7.

8. Kaul S, Menon M. Robotic radical prostatectomy: evolution from conventional to VIP. World J Urol. 2006:24(2):152-60.

9. Partin AW, Mangold LA, Lamm DM, Walsh PC, Epstein Jl, Pearson JD. Contemporary update of prostate cancer staging nomograms (Partin tables) for the new millennium. Urology. 2001;58(6):843-8.

10. D'Amico AV, Whittington R, Malkowicz SB, Wu YH, Chen M, Art M, et al. Combination of the preoperative PSA level, biopsy Gleason score, percentage of positive biopsies, and MRI T-stage to predict early PSA failure in men with clinically localized prostate cancer. Urology. 2000;55(4):572-7.

11. Curto F, Benijts J, Pansadoro A, Barmoshe S, Hoepffner JL, Mugnier C, et al. Nerve sparing laparoscopic radical prostatectomy: our technique. Eur Urol. 2006:49(2):344-52

12. Khoder WY, Waidelich R, Buchner A, Becker AJ, Stief CG. Prospective comparison of one year follow-up outcomes for the open complete intrafascial retropubic versus interfascial nerve-sparing radical prostatectomy. Springerplus. 2014;3:335.

13. Zheng T, Zhang X, Ma X, Li HZ, Gao JP, Cai W, et al. A matched-pair comparison between bilateral intrafascial and interfascial nerve-sparing techniques in extraperitoneal laparoscopic radical prostatectomy. Asian J Androl. 2013;15(4):513-7.

14. Ko WJ, Hruby GW, Turk AT, Landman J, Badani KK. Pathological confirmation of nerve-sparing types performed during robot-assisted radical prostatectomy (RARP). BJU Int. 2013;111(3):451-8.

15. Hoshi A, Usui Y, Shimizu Y, Tomonaga T, Kawakami M, Nakajima N, et al. Dorsal vein complex preserving technique for intrafascial nerve-sparing laparoscopic radical prostatectomy. Int J Urol. 2013;20(5):493-500.

16. Mortezavi A, Hermanns T, Seifert HH, Wild PJ, Schmid DM, Sulser T, et al. Intrafascial dissection significantly increases positive surgical margin and biochemical recurrence rates after robotic-assisted radical prostatectomy. Urol Int. 2012;89(1):17-24.

17. Khoder WY, Schlenker B, Waidelich R, Buchner A, Kellhammer N, Stief $C G$, et al. Open complete intrafascial nerve-sparing retropubic radical prostatectomy: technique and initial experience. Urology. 2012;79(3): 717-21. 
18. Choi YH, Lee JZ, Chung MK, Ha HK. Preliminary results for continence recovery after intrafascial extraperitoneal laparoscopic radical prostatectomy. Korean J Urol. 2012;53(12):836-42.

19. Stewart GD, El-Mokadem I, McLornan ME, Stolzenburg JU, McNeill SA Functional and oncological outcomes of men under 60 years of age having endoscopic surgery for prostate cancer are optimal following intrafascial endoscopic extraperitoneal radical prostatectomy. Surgeon. 2011:9(2):65-71.

20. Greco F, Hoda MR, Wagner S, Reichelt O, Inferrera A, Magno C, et al. Bilateral vs unilateral laparoscopic intrafascial nerve-sparing radical prostatectomy: evaluation of surgical and functional outcomes in 457 patients. BJU Int. 2011;108(4):583-7.

21. Asimakopoulos AD, Pereira Fraga CT, Annino F, Pasqualetti P, Calado AA Mugnier C. Randomized comparison between laparoscopic and robotassisted nerve-sparing radical prostatectomy. J Sex Med. 2011;8(5):1503-12.

22. Xylinas E, Ploussard G, Salomon L, Paul A, Gillion N, Laet KD, et al. Intrafascial nerve-sparing radical prostatectomy with a laparoscopic robotassisted extraperitoneal approach: early oncological and functional results. J Endourol. 2010;24(4):577-82.

23. Stolzenburg JU, Kallidonis P, Do M, Dietel A, Hafner T, Rabenalt R, et al. A comparison of outcomes for interfascial and intrafascial nerve-sparing radical prostatectomy. Urology. 2010;76(3):743-8.

24. Greco F, Wagner S, Hoda MR, Kawan F, Inferrera A, Lupo A, et al. Laparoscopic vs open retropubic intrafascial nerve-sparing radical prostatectomy: surgical and functional outcomes in 300 patients. BJU Int. 2010;106(4):543-7.

25. Neill MG, Louie-Johnsun M, Chabert C, Eden C. Does intrafascial dissection during nerve-sparing laparoscopic radical prostatectomy compromise cancer control? BJU Int. 2009;104(11):1730-3.

26. Stolzenburg JU, Rabenalt R, Do M, Schwalenberg T, Winkler M, Dietel A, et al. Intrafascial nerve-sparing endoscopic extraperitoneal radical prostatectomy. Eur Urol. 2008:53(5):931-40.

27. Menon M, Kaul S, Bhandari A, Shrivastava A, Tewari A, Hemal A. Potency following robotic radical prostatectomy: a questionnaire based analysis of outcomes after conventional nerve sparing and prostatic fascia sparing techniques. J Urol. 2005;174(6):2291-6 discussion 6.

28. Asimakopoulos AD, Annino F, D'Orazio A, Pereira CF, Mugnier C, Hoepffner $J$, et al. Complete periprostatic anatomy preservation during robot-assisted laparoscopic radical prostatectomy (RALP): the new pubovesical complexsparing technique. Eur Urol. 2010;58(3):407-17.

29. Potdevin L, Ercolani M, Jeong J, Kim IY. Functional and oncologic outcomes comparing interfascial and intrafascial nerve sparing in robot-assisted laparoscopic radical prostatectomies. J Endourol. 2009;23(9):1479-84.

30. Ihsan-Tasci A, Simsek A, Dogukan-Torer MB, Sokmen D, Sahin S, Bitkin A, et al. Oncologic results, functional outcomes, and complication rates of transperitoneal robotic assisted radical prostatectomy: single centre's experience. Actas Urol Esp. 2015;39(2):70-7.

31. Novara G, Ficarra V, Mocellin S, Ahlering TE, Carroll PR, Graefen M, et al. Systematic review and meta-analysis of studies reporting oncologic outcome after robot-assisted radical prostatectomy. Eur Urol. 2012;62(3): 382-404.

32. Weng $H$, Zeng $X T$, Li S, Meng XY, Shi MJ, He DL, et al. Intrafascial versus interfascial nerve sparing in radical prostatectomy for localized prostate cancer: a systematic review and meta-analysis. Sci Rep. 2017; 7(1):11454.

33. Savera AT, Kaul S, Badani K, Stark AT, Shah NL, Menon M. Robotic radical prostatectomy with the "veil of Aphrodite" technique: histologic evidence of enhanced nerve sparing. Eur Urol. 2006;49(6):1065-73; discussion 73-4

34. Fromont G, Baumert H, Cathelineau X, Rozet F, Validire P, Vallancien G. Intraoperative frozen section analysis during nerve sparing laparoscopic radical prostatectomy: feasibility study. J Urol. 2003;170(5):1843-6.

35. Rassweiler J, Marrero R, Hammady A, Erdogru T, Teber D, Frede T. Transperitoneal laparoscopic radical prostatectomy: ascending technique. J Endourol. 2004;18(7):593-9 discussion 9-600.

36. Eastham JA, Kattan MW, Riedel E, Begg CB, Wheeler TM, Gerigk C, et al. Variations among individual surgeons in the rate of positive surgical margins in radical prostatectomy specimens. J Urol. 2003;170(6 Pt 1):2292-5.

37. Atug F, Castle EP, Srivastav SK, Burgess SV, Thomas R, Davis R. Positive surgical margins in robotic-assisted radical prostatectomy: impact of learning curve on oncologic outcomes. Eur Urol. 2006;49(5):866-71 discussion 71-2.

38. Vickers AJ, Savage CJ, Hruza M, Tuerk I, Koenig P, Martinez-Pineiro L, et al. The surgical learning curve for laparoscopic radical prostatectomy: a retrospective cohort study. Lancet Oncol. 2009;10(5):475-80.

\section{Ready to submit your research? Choose BMC and benefit from:}

- fast, convenient online submission

- thorough peer review by experienced researchers in your field

- rapid publication on acceptance

- support for research data, including large and complex data types

- gold Open Access which fosters wider collaboration and increased citations

- maximum visibility for your research: over $100 \mathrm{M}$ website views per year

At BMC, research is always in progress.

Learn more biomedcentral.com/submissions 